\title{
O MUSEU NACIONAL DE HISTÓRIA NATURAL - UMA HISTÓRIA ATRIBULADA E UMA QUESTÃO EM ABERTO
}

\author{
LILIANA PÓVOAS ${ }^{(1)}$, CÉSAR LOPES $^{(1)}$, IRENEIA MELO ${ }^{(2)(3)}$, ANA I. CORREIA ${ }^{(2)(3)(4)}$ \& M. JUDITE ALVES ${ }^{(1)(3)}$
}

Resumo: Observando a legislação produzida a propósito do Museu de História Natural, nascido junto ao Palácio da Ajuda e
tornado Nacional na Escola Politécnica, percorre-se uma história atribulada em vista de uma solução organizativa,
mais vezes determinada por condicionalismos externos que por adequação ao exercício da sua missão específica. Neste
percurso é destacada uma situação particular, com início no ano de 1926, em que a solução organizativa legislada
parece contraditória com a, até então, apontada pelo museu. Esta solução acaba por ter reflexos que se estenderam até
ao final do século XX.

Palavras-chave: Real Museu e Jardim Botânico da Ajuda; Museu Nacional de História Natural; Escola Politécnica; Faculdade de Ciências da Universidade de Lisboa; Academia Real das Ciências de Lisboa; História da Museologia; Legislação

\begin{abstract}
:
"Museu Nacional de História Natural" - a troubled history and an open question.

The legislation related to the Natural History Museum, born near the Ajuda Palace and made National at the Polytechnic School, reveals a troubled history in terms of demand for an organizational solution, more often determined by external constraints rather than by an adaptation to the exercise of its specific mission. A particular situation that begun in 1926 is highlighted, when an organizational solution contradictory to the ongoing point of view of the museum was legislated. This solution turns out to have reflexes that extended until the end of the twentieth century.

Keywords: Real Museu e Jardim Botânico da Ajuda; Museu Nacional de História Natural; Escola Politécnica; Faculdade de Ciências da Universidade de Lisboa; Academia Real das Ciências de Lisboa; history of museology;
\end{abstract} legislation.

Received: 15 March, 2016; Accepted: 21 May, 2016

\begin{abstract}
"Museu de história natural de Lisboa, instituto que entre muitos e os mais célebres do paiz tem uma vida e merece uma biographia, quando mais não fôra, pelas vidas que n'elle em parte tem sido consumidas com proveito e gloria da nação, desde o final do seculo passado."

J. Bettencourt Ferreira, $1892^{1}$
\end{abstract}

\section{AS ORIGENS NA AJUDA}

No pós-terramoto de 1755, Portugal vive um momento de aproximação ao movimento científico e cultural que percorre a Europa das "luzes". Fonte de conhecimentos úteis e de recursos económicos, a História Natural está no centro desse movimento.

...."sendo manifesto que nenhuma cousa póde contribuir mais para o adiantamento da História Natural, do que a vista continua dos objectos que ella comprehende (....) He necessário (....) que se faça huma Collecção dos Productos, que pertencem aos tres Reinos da mesma Natureza". Estes propósitos, inscritos nos Estatutos da Universidade de Coimbra que materializam a Reforma Pombalina de 1772 , teriam já presidido, quatro anos antes, à decisão de se criar um Museu de História Natural em Lisboa (BRIGOLA 2003).
Assim, em 1768, sendo Rei D. José I e o governo presidido por Sebastião José de Carvalho e Melo, Marquês de Pombal, foi criado o Real Museu de História Natural e Jardim Botânico da Ajuda. O seu criador e primeiro director foi Domenico Vandelli (1735-1816)

Inicialmente destinado à educação e recreio dos príncipes e da família real foram reunidos exemplares, recolhidos ou adquiridos comercialmente em vários países europeus, constituindo-se colecções de acordo com os três Reinos da Natureza. O Museu de História Natural vai assumindo dimensão de serviço público, ao organizar colecções para diferentes estabelecimentos de ensino (entre os quais a Universidade de Coimbra), ao institucionalizar a internacionalização de relações

${ }^{(1)}$ Museu Nacional de História Natural e da Ciência. Email: lpovoas@museus.ul.pt

(2) Jardim Botânico/Museu Nacional de História Natural e da Ciência

${ }^{(3)} \mathrm{Ce} 3 \mathrm{C}$ - Centro de Ecologia, Evolução e Alterações Ambientais

${ }^{(4)}$ Departamento de Biologia Vegetal/Faculdade de Ciências da Universidade de Lisboa

${ }^{1}$ Cit. in: Brigola, 2003.

${ }^{2}$ Estatutos da Universidade de Coimbra, Livro III, Tit.VI, Cap. I, pag. 388.

${ }^{3}$ Domenico Agostino Vandelli veio para Portugal a convite do Marquês de Pombal. Foi director do Real Museu e Jardim Botânico da Ajuda entre 1768 a 1810 cargo que acumulou, a partir de 1772, com o de lente de Química e História Natural na Universidade de Coimbra. 
científicas e museológicas, ao ser reconhecido como instituto de investigação e ao abrir as portas à população um dia por semana e todos os dias aos alunos e curiosos de História Natural (BRIGOLA 2003). Porventura, o mais significativo empreendimento científico e museológico dessa época terá sido a realização das viagens philosophicas (1783$1790)^{4}$, expedições científicas destinadas à descrição dos territórios (incluindo a ocupação humana) e inventariação dos recursos naturais das colónias. Enriqueceram-se as colecções, elaboraram-se memórias, ilustrações e relatórios de trabalho de campo (PóvoAs et al. 2011).

O aumento das colecções e a necessidade de as expor eram incompatíveis com as exíguas dimensões do espaço ocupado pelo Museu. A sua posição excêntrica em relação à cidade também não facilitava o acesso do público e dos estudiosos.

Entretanto, a Academia Real das Ciências aspirava a constituir um Museu Nacional dedicado à História da Natureza, para o qual tinha já começado a reunir colecções. Esse interesse é declarado publicamente na Gazeta de Lisboa de 1 de Fevereiro de 1780 (Mocho \& PÓvOAS 2010) e reafirmado desde $1781^{5}$. Nesse sentido foi manifestando, também, o desejo de incorporar na Academia o Museu da Ajuda, o que acaba por ser concretizado por D. Maria II, através do Decreto de 27 de Agosto de 1836, que transfere para aquela instituição todas as colecções, arquivos e pertences do Real Museu de História Natural. Apenas o Jardim Botânico permanece na Ajuda mas sob a administração da Academia até 1839, data em que é incorporado na Escola Politécnica. (TAVARES 1957).

Em duas situações particulares que passamos a referir, as colecções do Museu da Ajuda são sujeitas a vicissitudes marcantes: quando na sequência da invasão francesa de 1808, Geoffroy Saint-Hilaire (1772-1844), às ordens de Napoleão, selecciona e remete espécimenes relevantes, para o Museu de História Natural de Paris, nomeadamente as "producçoens naturaes" provenientes do Brasil (BRIGOLA 2003); quando é feita a transferência do Museu de História Natural para a Academia Real das Ciências em 1836. Nessa deslocação "feita com precipitação e sem as devidas precauções" danificaram-se muitos exemplares, perderam-se e trocaram-se etiquetas. (MACHADO \& COSTA 1937).

\section{A PASSAGEM PELA ACADEMIA REAL DAS SCIENNCIAS DE LISBOA}

Uma vez na Academia, as colecções foram sendo ampliadas, estudadas e organizadas. No entanto, "a falta de salas apropriadas à sua acomodação e exposição, impedia o progresso das ciências naturais em Portugal, mostrando a necessidade da sua transferência" (LATINO COELHO 1863). Em 1856, a Academia das Ciências deixa de ter condições para abrir o Museu ao público e as colecções começam a apresentar sinais de degradação. Na impossibilidade do tesouro público atribuir a verba solicitada (como consta de relatório de Latino Coelho, então secretário geral) para o desenvolvimento do projecto do Museu Nacional, a própria Academia das Ciências considera que o Museu Nacional não "podia continuar a estar debaixo da sua administração por insuficiência de condições técnicas e materiais, sugerindo a ideia da sua instalação na Escola Politécnica" (MACHADO \& COSTA 1937), onde se reconhecia a existência de competências para o estudo das colecções e de espaços adequados para as instalar.

\section{A INSTALAÇÃO NA ESCOLA POLITÉCNICA...}

O Conselho da Escola Politécnica, em 1838, logo um ano após a sua fundação, solicita a transferência do Museu de História Natural para as suas próprias instalações, alegando a "necessidade de os professores de Ciências Naturais terem à sua disposição meios com que possam tornar o seu ensino teórico e prático ao mesmo tempo" (MACHADO \& CosTA 1937). Mas o pedido não colheu resposta positiva. Apenas a tutela do Jardim Botânico passa para a Escola Politécnica em 1839.

Um grande incêndio, em 1843, afecta gravemente o edifício da Escola Politécnica e, por consequência, as colecções existentes nos Gabinetes de História Natural. A reconstrução que se seguiu permite uma reorganização das suas instalações, que passam a dispor de amplas salas compatíveis com a acomodação do Museu. Mas só em 1858, D. Pedro V decreta que "o Museu de História Natural que foi, por decreto de 27 de Agosto de 1836, transferido para a Academia Real das Sciencias de Lisboa, passa para a Escola Politécnica" e que "as colecções de zoologia e mineralogia e todos os objectos pertencentes ao mencionado Museu são incorporados nos gabinetes de zoologia e mineralogia da mesma escola" e, ainda, que "estes dois gabinetes ficam constituindo as duas secções do Museu"6.

José Vicente Barbosa du Bocage (18231907), na qualidade de representante da Escola Politécnica, toma posse, em 8 de Maio de 1858 , das colecções de mineralogia, paleontologia, conchyologia e zoologia. E também de "todas as obras impressas, livros de registos e inventários, papeis avulsos e mobília diversa, por serem pertenças do dito Museu de História Natural, e com

\footnotetext{
${ }^{4}$ As viagens foram protagonizadas por quatro naturalistas formados por Vandelli, na Ajuda: João da Silva Feijó viaja para Cabo Verde, Joaquim José da Silva para Angola, Manuel Galvão da Silva para a Índia e Moçambique, Alexandre Rodrigues Ferreira para o Brasil.

${ }^{5}$ Breves instruções aos correspondentes da Academia das Sciências de Lisboa, sôbre remessas dos produçtos e notícias pertencentes à História da Natureza para formar um Museu Nacional, Lisboa, 1781. (Cit. in Machado e Costa, 1937).

${ }^{6}$ Carta de Lei de 9 de Março de 1858 .
} 
ele vieram para a Academia, no ano de 1836, das casas do Jardim Botânico da Ajuda"7.

A designação "Museu Nacional de Lisboa", já referida em Carta de Lei de 1861, é fixada por decreto que estabelece o regulamento do Museu, em 13 de Janeiro de 1862. Compreende então duas secções: Zoologia e Mineralogia.

Os herbários permaneceram na Academia até haver instalações adequadas na Politécnica, tendo sido solicitados apenas em $1875^{8}$. Transferidos em 1876, destacam-se pela sua importância os de Brotero, Vandelli, Welwitsch e Alexandre Rodrigues Ferreira. Para a instalação do Jardim é elaborado um projecto de regulamento em 1843, mas é a partir de 1873 que começa a ser posto em prática por acção de Andrade Corvo (1824-1890) e do Conde de Ficalho (1837-1903). Abre ao público em 1878 (TAVARES 1957) (Fig.1).

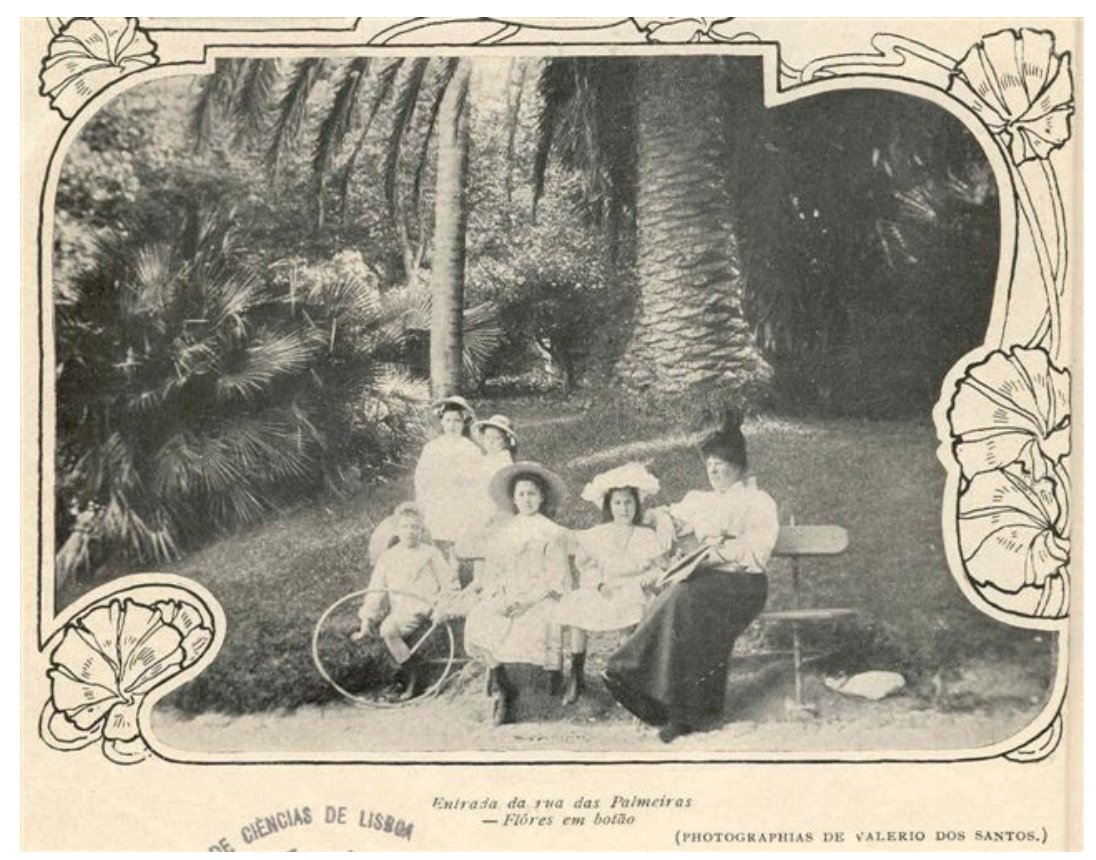

Fig. 1. Recanto do Jardim Botânico. Foto publicada na revista "Ilustração Portuguesa" em 1907. Fig. 1. Corner in the Botanic Garden. Photo published in the magazine "Ilustração Portuguesa" in 1907.

\section{4. ... E DA ESCOLA POLITÉCNICA À FACULDA- DE DE CIÊNCIAS}

A reforma do ensino universitário levada a cabo pelo governo provisório da República, em 1911, converte a Escola Politécnica em Faculdade de Ciências e integra-a na, então criada, Universidade de Lisboa. Segundo o "Plano Geral de Estudos nas Faculdades de Sciências", o artigo $45^{\circ}$ determina que: "Cada uma das Faculdades de Sciências" deve ter anexos: (...) Um museu e laboratório mineralógicos; Um museu e laboratório geológicos; Um jardim, museu e laboratórios botânicos; Um museu e laboratório zoológicos; Um museu e laboratório antropológicos" e que cada um destes estabelecimentos deveria ser dirigido "por um professor das respectivas especialidades, eleito pela Faculdade."

$\mathrm{Na}$ Faculdade de Ciências de Lisboa, o Museu Nacional de Lisboa passa a estabelecimento anexo mas mantém a sua autonomia tanto do ponto de vista administrativo como financeiro.
Este modelo de organização terá suscitado a necessidade de uma redefinição das funções e competências do Museu em relação à Faculdade de Ciências (Fig. 2).

Assim, em $1919^{10}$, são regulamentadas as atribuições dos estabelecimentos anexos às Faculdades. Reza no preâmbulo: "Destes estabelecimentos um dos mais importantes, pela quantidade $e$ qualidade dos exemplares que constituem as suas colecções é o Museu Nacional, com as suas três secções (....). Devem, sem dúvida, estes estabelecimentos continuar anexos à Faculdade de Sciências (...) mas autónomos pelo que respeita às suas funções. Institutos de investigação scientífica, nos quais não só há a fazer estudos de taxinomia, mas experiencias e indagações em todos os ramos das sciências naturais puras e aplicadas (...). Tal objectivo é completamente diverso das funções de ensino dos cursos; pode ser dele complemento, mas não parte integrante, sob pena de nem os cur-

${ }^{7}$ Cópia do termo lavrado pela Academia Real das Ciências sobre a transferência para a Escola Politécnica do Museu de História Natural, AHMUL, cx 2047.

${ }^{8}$ Minuta da carta do Conselho da Escola Politécnica de 8 de Março de 1875, AHMUL, cx 2047.

${ }^{9}$ Decreto com força de lei, de 12 de Maio de 1911.

${ }^{10}$ Decreto n. ${ }^{\circ} 5.689$ de 10 de Maio de 1919. 


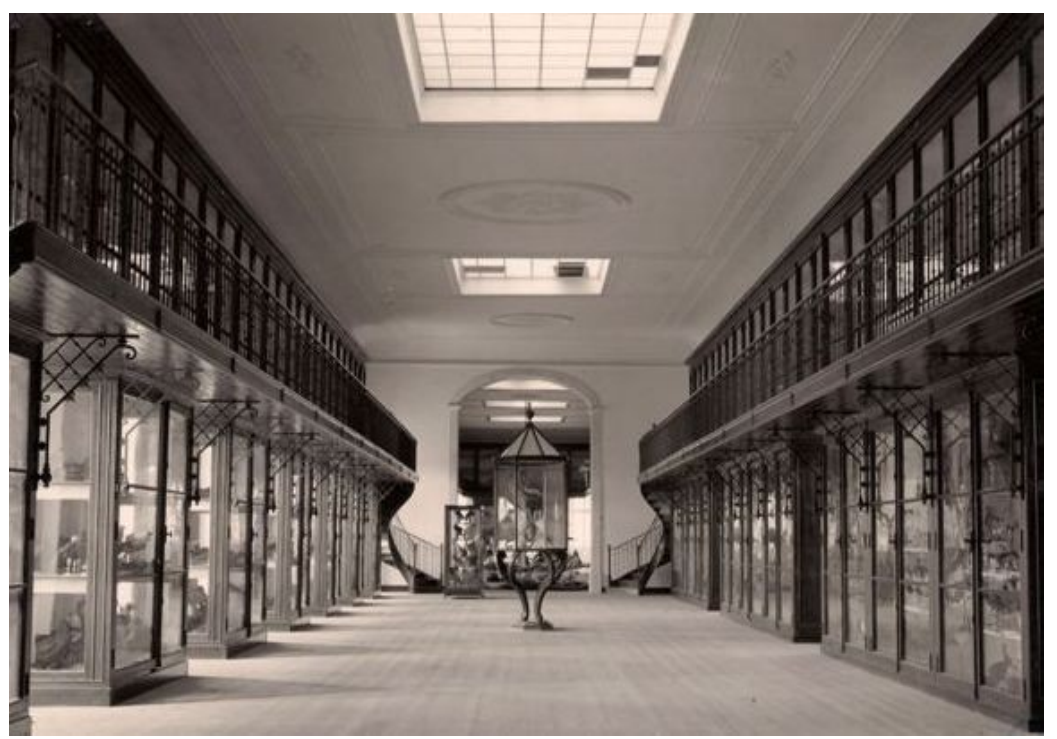

Fig. 2. Galeria de Zoologia na primeira metade do séc. XX. Foto AHMUL.

Fig. 2. Zoology Gallery in the first half of the $20^{\text {th }}$ century. Photo AHMUL.

sos nem o Museu Nacional satisfazerem o fim a que devem visar. É consequência lógica da sua indole esta independência, o que não importa que o Museu não auxilie o ensino, pelo contrário, mas nas condições e modo próprio à sua feição." Decreta, logo no artigo $1^{\circ}$, que "O Museu Nacional continua anexo à Faculdade de Sciências da Universidade de Lisboa, mas com funções autónomas e independentes dos serviços escolares", e que "os serviços do Museu e serviços escolares têm quadro privativo de pessoal e dotação própria". Na atribuição do quadro de naturalistas do museu são definidas as suas três secções: "Secção Zoológica e Antropológica (Museu Bocage); Secção Botânica; Secção Mineralógica e Geológica”. Tal como no decreto de 1911, determina (artigo $5^{\circ}$ ) que cada uma destas secções deverá ser dirigida "por um professor da respectiva especialidade, eleito pelo Conselho da Faculdade".

Apesar desta clarificação relativa à autonomia e independência das funções do Museu, presume-se que motivada por um quadro institucional eventualmente permeável a outras interpretações da relação Museu / Faculdade, poucos anos mais tarde, em 1926, é adoptada uma nova estrutura organizativa do Museu, não conforme com o modelo então vigente, contrária ao estipulado em 1919 e oposta às perspectivas de organização que se estavam a desenhar na sua esfera.

Assim, em 1926 é consignada, por decreto ${ }^{11}$, a designação "Museu Nacional de História Natural" mas, de acordo com essa mesma legislação, cada uma das três secções do museu (Botânica, Zoologia e Geologia) tornam-se formalmente independentes entre si e passam a ser outros tantos estabelecimentos, anexos às secções homólogas da Faculdade de Ciências, ficando sob a direcção dos respectivos Professores decanos de cada uma das áreas científicas afins do museu. $\mathrm{O}$ artigo $18^{\circ}$ deste decreto, e no que respeita ao Museu Nacional de História Natural (MNHN), estabelece que "As três secções do Museu Nacional de História Natural, (...)” são consideradas "outros tantos estabelecimentos: Museu e Jardim Botânico, Museu Mineralógico e Geológico, e Museu Zoológico e Antropológico (Museu Bocage) com a Estação de Zoologia Maritima anexa."

Para melhor compreensão das relações orgânicas entre museu e faculdade refere-se ainda o estipulado no regulamento de 1932 da Faculdade de Ciências da Universidade de Lisboa (FCUL) e estabelecimentos anexos ${ }^{12}$. De acordo com este documento (capítulo IX, $\operatorname{Art}^{\circ}$ 146) a FCUL "compreende: Biblioteca; Gabinete de matemática; Gabinete de desenho; Laboratório de fisica; Laboratório de química; Laboratório de mineralogia e geologia; Laboratório de botânica; Laboratório de zoologia e antropologia". No artigo 147 é determinado que "São estabelecimentos anexos à Faculdade de Ciências da Universidade de Lisboa, gozando de autonomia administrativa análoga à que é concedida à Faculdade, os seguintes: Observatório Astronómico; Observatório Central Meteorológico (Infante D. Luiz); Museu Nacional de História Natural", em relação ao qual se continua a considerar que as três secções, designadas Museus, são outros tantos estabelecimentos (Fig. 3).

${ }^{11}$ Decreto ${ }^{\circ} 12.492$ de 14 de Outubro de 1926.

${ }^{12}$ Decreto $^{\mathrm{o}} 20.747$, de 12 de Janeiro de 1932. 


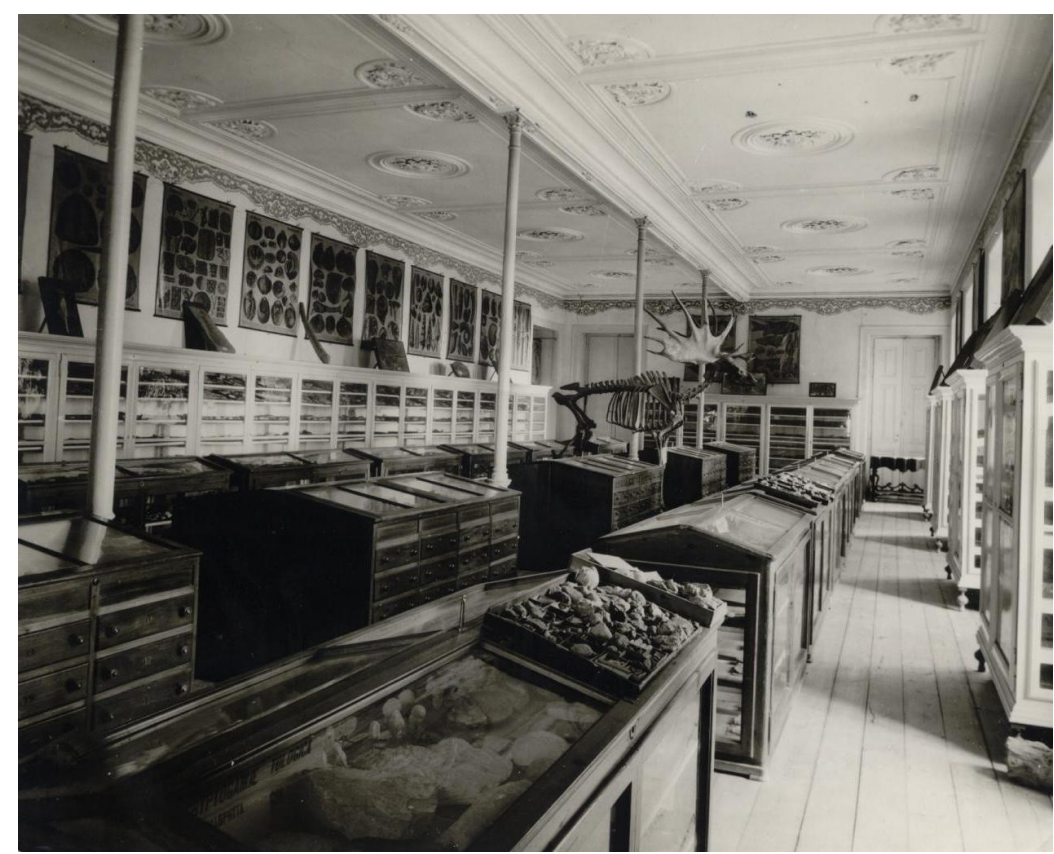

Fig. 3. Sala de Paleontologia. Foto Abreu Nunes, 1958. AHMUL.

Fig. 3. Palaeontology room. Photo Abreu Nunes, 1958. AHMUL.

Dado novo é a determinação do $\operatorname{Art}^{\circ} 149^{\circ}$ : "Cada um dos estabelecimentos mencionados nos artigos $146^{\circ}$ e $147^{\circ}$ será dirigido por um professor catedrático, eleito pelo conselho da Faculdade. São reunidas sob a mesma direcção cada uma das secções do Museu Nacional de História Natural e o Laboratório da mesma designação."

É no decurso do processo de democratização do país e da própria Universidade, a partir de meados dos anos 1970, que vai emergindo uma perspectiva de redefinição do papel social do Museu Nacional de História Natural e de reforma das suas estruturas, que assume uma maior urgência e vem a tomar contornos precisos na sequência do incêndio de 1978. Esta calamidade vai afectar gravemente o edifício e destruir, literalmente, todas as colecções zoológicas e antropológicas e cerca de metade das colecções geológicas. O Jardim Botânico e os herbários não foram afectados. $\mathrm{O}$ esforço de reconstituição do património e dos espaços permite que, paulatinamente, se vão desenvolvendo colecções e actividades expositivas, educacionais e de divulgação. Para além do esforço comum na produção de conhecimento científico, esta dinâmica envolve de forma particular cada um dos "Museus e Laboratórios" de acordo com as prioridades e especificidades de cada um destes organismos, num caminho que levará à reorganização e reunificação das componentes organizacionais estruturantes do Museu Nacional de História Natural.

A pautar este percurso, assinalam-se as decisões tomadas pela Faculdade de Ciências, em Assembleia Geral de 4 de Abril de 1978, logo nos dias imediatos ao desastre de 18 de Março, no sentido da reestruturação e reinstalação do Museu Nacional de História Natural no edifício da Rua da Escola Politécnica e de criação e instalação do Museu de Ciência da Universidade de Lisboa nesse mesmo edifício. No ano seguinte, a Secretaria de Estado do Ensino Superior e Investigação Científi$\mathrm{ca}^{13}$ nomeia uma Comissão de Reorganização do Museu Nacional de História Natural constituída pelos presidentes dos Conselhos directivos dos três Museus e Laboratórios (Carlos Almaça, Fernando Catarino, Carlos Matos Alves) e por um investigador de cada destes organismos (António Soares, Ireneia Melo e Filomena Diniz). O Relatório produzido por esta Comissão, datado de Dezembro de 1979 , vem a constituir um importante documento de trabalho e a influenciar fortemente a redação de uma nova proposta de Estatutos do Museu apresentada em Novembro de 1989, pelos três directores dos três "Museus e Laboratórios", respectivamente os Professores Carlos Almaça, Fernando Catarino e Galopim de Carvalho.

\section{NOVOS PROJECTOS, NOVAS ESTRU- TURAS}

$\mathrm{Na}$ sequência deste trajecto tem início, em 1992, um processo de formalização de um novo projecto e de uma nova estrutura, com a instituição de novos estatutos, provisórios por um período de dez anos, regulamentando a autonomização do Museu, a fusão dos quadros dos três antigos “estabelecimentos anexos" - os "Museus e Labora-

${ }^{13}$ Despacho 89/79, da Secretaria de Estado do Ensino Superior e Investigação Científica. 
tórios" - mas mantendo a ligação à Faculdade de Ciências que constitui a tutela científica do Museu ${ }^{14}$. Os estatutos definitivos são publicados em $2003^{15}$. Através deles é criada a figura "Departamento" correspondente à estrutura organizativa dos antigos "Museus e Laboratórios" e o Museu Nacional de História Natural é autonomizado da Faculdade de Ciências, constituindo uma unidade orgânica dentro da Universidade da Lisboa.

Em conformidade com os novos estatutos são considerados órgãos do Museu $\left(\operatorname{Art}^{\circ} 7^{\circ}\right.$ ) a Assembleia do Museu, a Comissão Técnico-Científica (CTC) e a Direcção, a qual segundo o $\operatorname{art}^{\mathrm{o}} 8^{\mathrm{o}}$, é "constituída por três membros, um presidente e dois vogais, nomeados pelo Reitor da Universidade de Lisboa por um periodo de 3 anos, renovável por igual periodo, ouvida a Comissão Científica do Senado, sob proposta da CTC, de entre os professores e investigadores da Universidade de Lisboa, sendo obrigatoriamente um de cada uma das três áreas, Mineralogia e Geologia, Biologia Vegetal, Zoologia e Antropologia." Os estatutos determinam ainda que "os membros da direcção elegerão entre si o presidente da direcção" e que "a presidência da direcção é obrigatoriamente rotativa entre as três áreas" científicas correspondentes a cada um dos departamentos.

Ainda em 2003, Galopim de Carvalho (Fig. 4), que com esta reflexão queremos homenagear, cessa as funções de director do Museu Nacional de História Natural e, em relatório, caracteriza a actividade correspondente aos anteriores dez anos:

"O processo de democratização da Universidade, o incêndio de 1978 (...) e a transferência da Faculdade de Ciências para as novas instalações no Campo Grande são as condições e o pretexto para o início de um importante periodo de reorga- nização interna e de tomada de consciência das funções educativa, cultural e social do Museu. Desta forma, abrir as portas à população e a outros utilizadores, ser estrutura de apoio ao ensino, à investigação e à divulgação científica, ser guardião dos testemunhos da Natureza, torná-la inteligivel e abordar a forma como se processa a sua análise, sensibilizando para os problemas que decorrem da relação do Homem com o seu Meio, são, hoje, os novos objectivos e desafios que ditam a experiência que temos vindo a percorrer.

Segundo os Estatutos aprovados, o Museu Nacional de História Natural da Universidade de Lisboa dispõe (...) de bases organizativas que viabilizem a sua abertura a novos utilizadores e a sua definição como um local de encontro entre a Universidade, o Museu, a Cidade e o País.

Partindo destes pressupostos, e na sequência da produção de conhecimento científico através das linhas de investigação em curso, cujos resultados são objecto de publicações, o Museu (...) promove a preservação de sítios de interesse patrimonial, produz ou acolhe, muitas vezes em colaboração com outras entidades, exposições temáticas e temporárias no âmbito das áreas científicas que cultiva, é sede de conferências, debates e espaço de desenvolvimento de diferentes programas pedagógicos (da educação ambiental à cristalografia). Promove, ainda, outros tipos de eventos, tais como as Feiras Internacionais de Minerais, Gemas e Fósseis.

Na sequência de uma política de abertura ao exterior, o "espaço Museu" é, ainda, frequentemente palco de diversas manifestações (...) a perspectiva que temos é a de que o Museu pode ser uma estrutura que se utiliza em vez de um produto que se consome" (GALOPIM DE CARVALHO 2004).

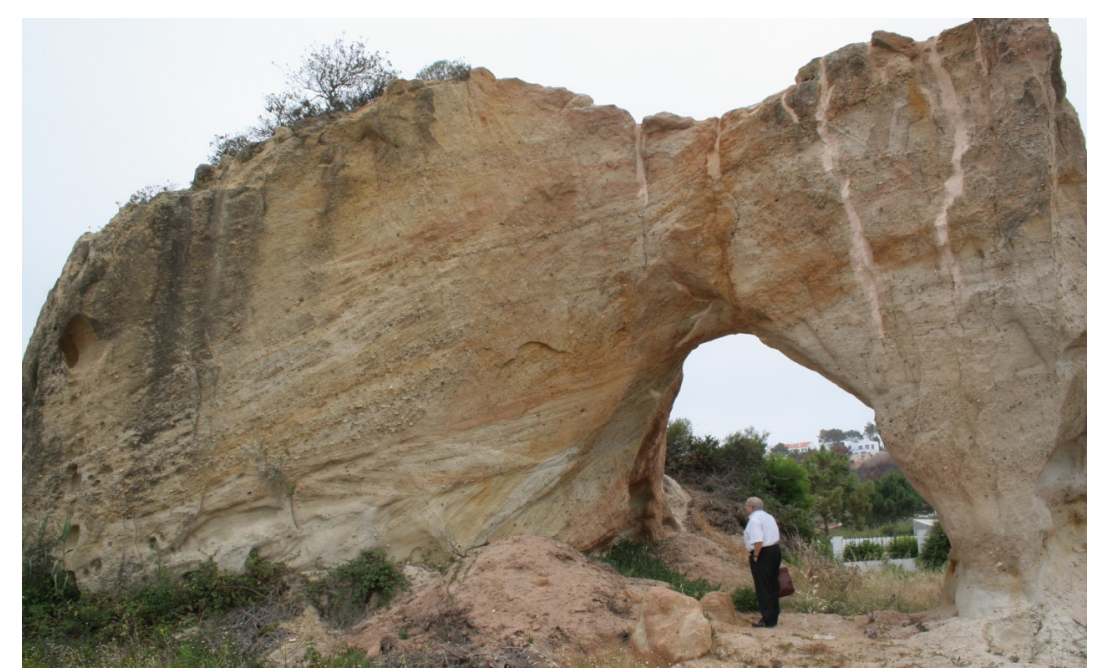

Fig. 4. Galopim de Carvalho na "Pedra Furada" da Foz do Arelho (Caldas da Rainha). Foto 2003. AFMUL.

Fig. 4. Galopim de Carvalho in the " Pedra Furada " in Foz do Arelho (Caldas da Rainha). Photo 2003. AFMUL.

\footnotetext{
${ }^{14}$ Diário da República II Série, $\mathrm{n}^{\circ} 142$, de 23 de Junho de 1992.

${ }^{15}$ Despacho ${ }^{\circ} 11002 / 2003$ ( $2^{\mathrm{a}}$ série), de 9 de Maio, Diário da República no 128 , II Série, de 3 de Junho
} 
Este balanço assinala o epílogo do período experimental dos novos estatutos. Na aplicação da sua versão definitiva é desenvolvida uma nova prática organizativa e reforçada a acepção comum da missão ${ }^{16}$ do Museu Nacional de História Natural. Neste novo quadro, o Museu, define-se como um "organismo da Universidade de Lisboa, vocacionado para a investigação científica e activida- des de extensão cultural," (...) considerando que "a sua missão é a de contribuir para o desenvolvimento da cultura científica na área dos recursos naturais e a de divulgar as condições para que os cidadãos ganhem progressivamente consciência do lugar que ocupam no planeta que habitam e do uso sustentável dos recursos" (Fig. 5 e 6).
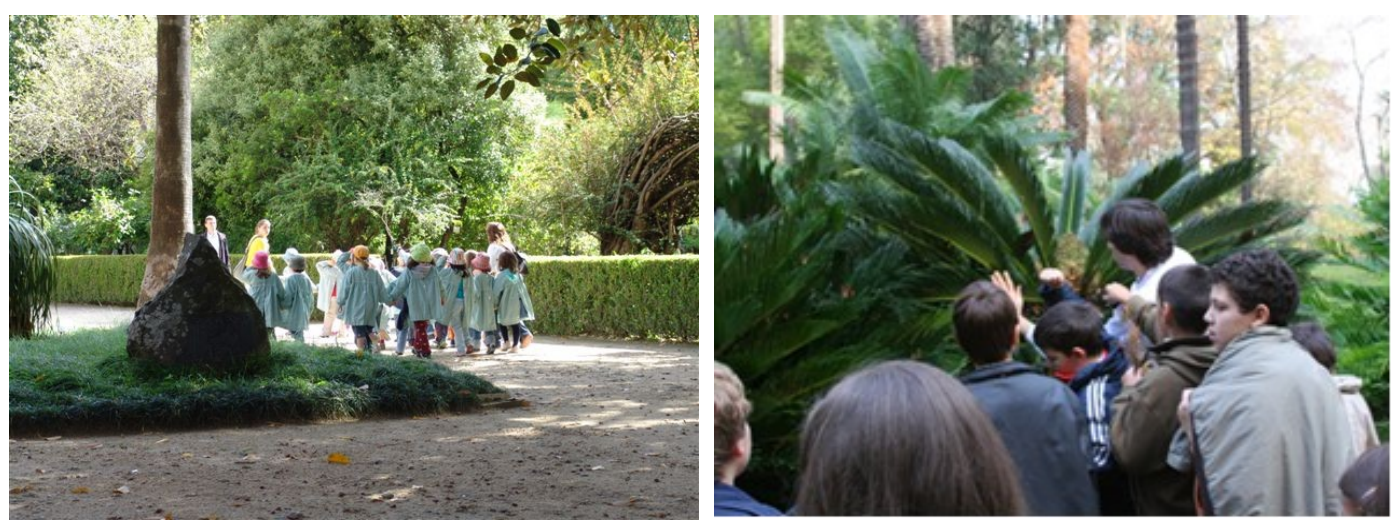

Fig. 5. Actividades de serviço educativo no Jardim Botânico. Fotos José Cardoso. AFMUL.

Fig. 5. Educational activities in the Botanical Garden. Photos José Cardoso. AFMUL.
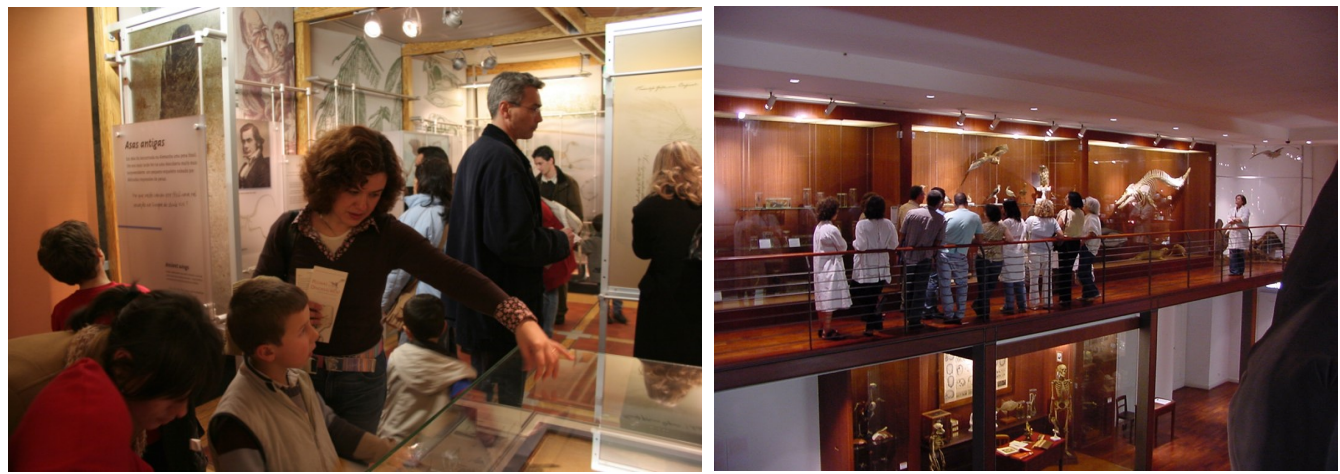

Fig. 6. Nas exposições "Colecções de Naturalista" e "Plumas em Dinossáurios". Fotos 2005. AFMUL.

Fig. 6. In the exhibitions "Naturalists Collections" and "Feathers in Dinosaurs ". Photos 2005. AFMUL.

Atingida esta plataforma integradora dos diferentes contributos e experiências, algumas de grande impacte na vida da cidade e de grande significado num tempo em que a divulgação da ciência ia ganhando espaço de cidadania, a dimensão organizativa no quadro da Universidade de Lisboa passa a ser de novo uma prioridade. Salienta-se o ano de 2011, marcado por profundas alterações na estrutura organizativa do Museu Nacional de História Natural e do Museu de Ciência da Universidade de Lisboa.

Como uma primeira etapa desta reforma, refere-se a nomeação, pelo Conselho Geral da Universidade de Lisboa, de uma comissão para elaboração de proposta de novos estatutos (coerentes com os estatutos da Universidade de Lisboa já conformes com o novo Regime Jurídico das Instituições de Ensino Superior ${ }^{17}$ ) e a consequente suspensão dos estatutos do museu que vigoraram até Dezembro de 2010.

Num segundo momento, é definido um novo modelo de organização do "Complexo museológico da Politécnica/Museus da Politécnica", sendo adoptada, como nova designação do "Complexo", a denominação "Museu Nacional de História Natural e da Ciência". Em concordância com esta medida, o Conselho Geral da Universidade de Lisboa, em Outubro de 2011, cria a Unidade Museus da Universidade de Lisboa que, sucedendo às unidades Museu Nacional de História Natural / Museu de Ciência da Universidade de Lisboa, integra estas

\footnotetext{
${ }^{16}$ Programa e Relatório de Actividades, Museu Nacional de História Natural, Lisboa, 2006.

${ }^{17}$ Lei $\mathrm{n}^{\mathrm{o}} 62 / 2007$, de 10 de Setembro.
} 
duas entidades museológicas ${ }^{18}$. Esta nova unidade orgânica passa a ser a "detentora" de todos os bens e activos (quadros de pessoal, orçamento, colecções...) das anteriores unidades orgânicas Museu Nacional de História Natural e Museu de Ciência da Universidade de Lisboa. As diferentes áreas disciplinares ficam assim consignadas na estrutura organizativa, dando corpo à curadoria de colecções, à investigação científica em curso e à comunicação de ciência junto dos públicos dos museus.

\section{UMA QUESTÃO AINDA EM ABERTO...}

Durante todo este processo, e mesmo já antes, o Museu, os seus directores e funcionários foram frequentemente interpelados ou depararam com a perplexidade de muitos frequentadores, elementos do público, colegas de outras instituições e, até, da própria tutela perante a estrutura organizativa do Museu Nacional de História Natural que implicava três museus dentro de um outro. Por vezes a situação era tomada como resultando da prevalência de interesses particulares ou de grupo, enfim, considerações que não pareciam reflectir exactamente a situação que internamente era vivida.

Fomos, por isso, tentar compreender as razões e o contexto que levaram à decisão de 1926 de tornar as três secções independentes entre si. Face às consequências para a instituição, que motivações estariam na origem desta decisão?

Consultámos as actas do Conselho Escolar da Faculdade de Ciências desde 1919 até 1930 e a correspondência das Secções de Zoologia e Geologia durante o mesmo período. Escolhemos a data de 1919 porque nesse ano o Decreto de 10 de Maio considera que as missões e as funções do Museu Nacional e da Faculdade de Ciências não deveriam ser confundidas porque são diversas apesar de complementares.

$\mathrm{Na}$ correspondência referida foi encontrada uma carta ${ }^{19}$ datada de Julho de 1818 assinada por Bernardo Ayres (1868-1931), director do Museu Zoológico da Universidade de Coimbra e lente dessa Universidade, na qual esta opinião era partilhada com elemento do Museu Bocage que não nos foi possível identificar com segurança. Talvez esta perspectiva tenha influenciado o conteúdo do Decreto de 1919.

A seguinte referência significativa para $\mathrm{o}$ futuro do Museu Nacional de História Natural, encontra-se nas Actas do Conselho Escolar e é exactamente do ano de 1926. Durante a reunião de 24 de Abril $^{20}$, o Professor Ricardo Jorge (1886-
1975) defendeu que as três secções do Museu deveriam ser instaladas em todo o $1^{\circ}$ andar do edifício da Faculdade de Ciências e as aulas no R/C. Ainda na reunião de 5 de Junho ${ }^{21}$ chamava a atenção para a necessidade de remodelação das instalações do museu, para o unificar e dar-lhe efectividade. Ninguém no Conselho Escolar se pronunciou contra esta proposta. A 19 de Junho, Artur Ricardo Jorge foi nomeado Ministro da Instrução Pública no governo de Gomes da Costa, cargo que ocupou apenas durante 20 dias, até ser demitido na sequência do golpe de estado ${ }^{22}$ de Óscar Carmona. Ao contrário do espectável, em 14 de Outubro de 1926, o Decreto já referido e, surpreendentemente, ainda assinado por Ricardo Jorge, entre outros, consigna a designação Museu Nacional de História Natural ao mesmo tempo que torna cada uma das suas três secções autónomas administrativamente $\mathrm{e}$ as denomina como museus - o Museu Mineralógico e Geológico; o Museu Zoológico e Antropológico; o Museu e Jardim Botânico. Desde então o MNHN é apenas a denominação que integra as suas três antigas secções que passam a ser agora consideradas unidades museológicas independentes entre si e anexas às Secções da Faculdade de Ciências das respectivas áreas científicas.

Não conseguimos encontrar qualquer reacção a esta decisão nas Actas do Conselho Escolar que se seguiram àquela data. Mas, na sessão de 5 de Fevereiro de 1927, está registado que os directores de cada um dos três museus ${ }^{23}$, obrigatoriamente Professores da Faculdade, enviaram ao reitor da Universidade a composição dos respectivos Conselhos Administrativos. Estas decisões encontram confirmação na legislação de 1928, quando em resultado da crise económica instalada é decretada redução de pessoal, das despesas constantes dos orçamentos e estabelecido que "são reunidos sob direcção única pelo respectivo Professor os serviços dos laboratórios e museus anexos ${ }^{24, "}$

Nos documentos consultados não descobrimos a razão expressa pela qual o museu foi dividido. Só sabemos que esta decisão levou a que todos os recursos em capital e trabalho disponíveis fossem canalizados para o ensino e a investigação de cada uma das três áreas científicas. Ainda na década de 1970, o orçamento da Faculdade não incluía fundos para as secções de Ciências Naturais: eram financiadas pelos orçamentos dos museus (GALOPIM DE CARVALHO, com. pess.).

Desde a legislação de 1926, que antes referimos, o crescimento das colecções decorre quase exclusivamente dos trabalhos de investigação cien-

\footnotetext{
${ }^{18}$ Despacho n ${ }^{\circ} 643 / 2014$ de 14 de Janeiro, Diário da República, $2^{a}$ série, № 9.

${ }^{19}$ Carta de Bernardo Ayres de resposta a carta proveniente do Museu Bocage. AHMUL, Arq.MB.CN-A24.

${ }^{20}$ Acta da Sessão do Conselho Escolar da Faculdade de Ciências da Universidade de Lisboa de 24 de Abril de 1926, AHMUL, Lv.1438.

${ }^{21}$ Acta da Sessão do Conselho Escolar da Faculdade de Ciências da Universidade de Lisboa de 5 de Junho de 1926, AHMUL, Lv.1439.

${ }^{22}$ Derrube e prisão do general Gomes da Costa assumindo Óscar Carmona a Presidência do Ministério a partir de 9 de Julho de 1926.

${ }^{23}$ Acta da Sessão do Conselho Escolar da Faculdade de Ciências da Universidade de Lisboa de 5 de Fevereiro de 1927, AHMUL, Lv. 1439

${ }^{24}$ Decreto no 15:977, de 24 de Setembro de 1928, Diário do Governo nº 220, I Série, p.p. 1972-1975.
} 
tífica, cartografia e de raras doações. Não resulta, também, de compras, como no fim do século XIX e início do século XX. A componente expositiva cristaliza e regride, o museu abria ao público somente um dia por semana, já não era mais possível distinguir o que era actividade do museu ou da Faculdade, mesmo nos arquivos de correspondência. Esta situação mantém-se até meados dos anos de 1970. Só começou a mudar na sequência do processo de democratização do país quando ganha terreno a ideia de que o museu tinha uma missão específica a cumprir e uma responsabilidade social. Como já referido, este debate foi reforçado depois do incêndio de 1978 que levou à transferência da Faculdade para outras instalações e colocou o museu sob a dependência directa da Reitoria da Universidade de Lisboa.

\section{O FUTURO}

A herança que o velho museu de história natural transporta para a novel organização Museus da Universidade de Lisboa/Museu Nacional de História Natural e da Ciência será a constatação da sua justificação social, o seu património cultural e científico, uma história atribulada e a experiência recente de um curto período de grande autonomia, correspondente a uma fase de grande dinamismo na comunicação de ciência, na identificação e proteç̧ão do património natural, na promoção de uma consciência ambiental.

\section{BIBLIOGRAFIA}

Brigola, J. C. P. 2003. Colecções, gabinetes e Museus em Portugal no século XVII, Textos Universitários de Ciências Sociais e Humanas, Fundação Calouste Gulbenkian - Ministério da Ciência e do Ensino Superior, Coimbra.

Galopim DE CARvalho, A.M. (Coord.). 2004. MMG/ MNHN/UL (1993-2003) - Investigação Científica, Museologia, Extensão Pedagógica, Defesa do Património Geológico. Lisboa, Museu Mineralógico e Geológico (MNHN).

LAtino Coelho, J. M. 1863. "Relatório dos trabalhos da Academia Real das Ciências lido na sessão pública de 20 de Fevereiro de 1859". História e Memórias da Academia Real das Ciências de Lisboa, nova série, tomo II, parte II.

Machado e Costa, A. A. O. 1937. Escola Politécnica de Lisboa - o Museu Mineralógico e Geológico. Revista da Faculdade de Ciências de Lisboa. 3: 5-60

Mocho, P. \& PóvoAs, L. 2010. Crânios fósseis de cetáceos (Mysticeti, Cetotheriidae) do Museu Nacional de História Natural, Lisboa: um breve enquadramento histórico. In: A. Santos, E. Mayoral, G. Meléndez, C.M. Silva \& M. Cachão (Eds.), III Congresso Ibérico de Paleontologia / XXVI Jornadas de la Sociedad Española de Paleontologia, Lisboa, 7 10 Julho. Publicaciones del Seminario de Paleontologia de Zaragoza. 9: 184-187

Póvoas, L.; Lopes, C.; Melo, I.; Correia, A.I.; Alves M.J.; Cardoso, H. \& Galopim DE CARvalho, A.M. 2011. O Museu Nacional de História Natural. In: Património da Universidade de Lisboa - Ciência e Arte. M C. Lourenço, MJ Neto (Coord.). Lisboa, Universidade de Lisboa e edições Tinta da China:17-34

TAVAres, C. N. 1957. Guia do Jardim Botânico da Faculdade de Ciências de Lisboa, Porto, Imprensa Portuguesa. 